\title{
The Irritant Constituent of Anti-Leprotic Oils.
}

H. Paget, J. W. Trevan, A. M. P. Attwood. (Abstract of a Paper published in "The International Journal of Leprosy," 1934 ; 2, 149.)

$\mathrm{O}$ BSERVATIONS made in these laboratories and elsewhere during the last few years have shown that chaulmoogric and hydnocarpic acids and their derivatives deteriorate on long exposure to air. For instance, aqueous solutions of the sodium salts of the acids hydnocarpus wightiana oil become darker in colour and cloudy, with a lowering of the $\mathrm{pH}$ and the optical rotation. The chaulmoogric ester of hydroxymercuri- $m$-hydroxybenzaldehyde (1), which is completely soluble in oils when freshly made, loses this property on long keeping. Muir (2) and others have pointed out that oil expressed from stale seeds or which has been exposed unduly to light and air is more irritant on injection than a fresh sample.

Pain caused on injection of these preparations may be due to two factors. First, there is the irreducible minimum caused on injection of fresh neutral oil, or of carefully prepared ethyl chaulmoograte or hydnocarpate. This is to be regarded as inherent, and bound up with the chemical 
constitution and physiological action of these acids. There may also be a second factor, artificial in origin and variable in degree, which has been attributed to incipient rancidity in the oil, to decomposition during distillation in the case of the esters (3), or to excessive alkalinity in the case of the sodium salts, until Jackson (4) showed that $\mathrm{pH}$ could not be correlated with the degree of irritation. As, however, it seemed possible that in each of these cases the second factor in pain production might be due to a single cause, the authors have conducted a search for an irritant substance in the fraction, constituting about 25 per cent. of the total acids of the oil, the composition of which is still undetermined. For this purpose it was convenient to use sapucainha oil, of which a quantity was already under investigation and which resembles very closely the oil of hydnocarpus wightiana $(5,6,7)$.

The chemical part of this work consisted in :-

1. The isolation of the oil from the seed by extraction with carbon tetrachloride, and confirmation of its resemblance to hydnocarpus oil.

2. The preparation of the fatty acids from the oil by saponification, and their separation by crystallisation from alcohol into $A$, the "crystalline acids," and $B$, the "residual" or " syrupy acids."

3. The further separation of the residual acids $B$ into the " oily acid," the "keto-acids " and the " tarry acids."

Cold processes of separation were used as far as possible, since the work of previous authors $(8,9)$ indicates that neither the residual acids nor their esters can be distilled without decomposition. Each of these fractions was converted to the sodium salts and the ethyl esters for biological examination. The crystalline acids $A$ amounted to about 56.5 per cent. of the total acids and had all the properties of a mixture of chaulmoogric and hydnocarpic acids.

The " oily acid" (5 per cent.) was obtained as a golden yellow oil, solidifying at $10-15 \mathrm{deg}$. C., and probably still containing some dissolved crystalline acids. The "ketoacids" (4.5 per cent.) formed a white crystalline solid melting at 101-103 deg. C. The "tarry acids" (about 9 per cent.) were obtained as a viscous and intractable black residue, forming a copper salt insoluble in acetone and ether.

The most interesting of these components from the point of view of the treatment of leprosy is the "tarry acids." It is highly irritating on injection in the form of its ethyl esters, which cannot be distilled without decomposition 
even under $0.5 \mathrm{~mm}$. pressure. It may also prove to be identical with the acid resulting from the long exposure of oils, or esters of chaulmoogric and hydnocarpic acids to air. It seems most likely that it constitutes the additional irritant factor in oils and esters which have deteriorated.

For comparison with the esters of the " tarry acids,' a quantity of the ethyl esters of the crystalline acids was exposed to light and air in shallow dishes during the summer months. It showed a rise in acid value and specific gravity and a fall in iodine absorption value, which indicates a lower degree of unsaturation in the molecule. The optical rotation was greatly reduced. In each of these respects the exposed esters resemble the esters of the "tarry acids," and it is hoped by further work to establish definitely that these two products consist largely of the same constituent.

The other components of the total acids, viz., the crystalline acids (A), the " oily acids " and the " keto-acids," yield ethyl esters, which distil without apparent decomposition under reduced pressure, and there is no indication that they become irritant as a result of such distillation. No obvious decomposition occurred when the ethyl esters of the crystalline acids were distilled even under atmospheric pressure, although a small increase in acid value and fall in optical rotation and iodine absorption value indicate that a slight change is produced by overheating and that it is of the same character as that resulting from exposure to air ; these changes are not further affected by steaming.

*The test for irritant properties was carried out by the injection of the material into the skin of the guinea pig, either undiluted or diluted with bland solvents. The hair was removed by clipping and the use of depilatory pastes was avoided as the skin becomes unduly sensitive to the necrotic action of the drug. The diluents used were ethyl oleate and commercial " liquid paraffin," both of which were absorbed, usually without more than a slight trace of redness and with no necrosis. The blandest members of the chaulmoogric acid series studied, viz., iodised ethyl esters, produced very little more reaction than the diluent itself. With the more irritating members of the series a greater degree of vascular reaction was followed by thickening, necrosis, and the formation of a black scab which sloughed off. The most irritant produced complete necrosis of an area up to one centimetre or more in diameter. If the drug was diluted before injection, the area of the scab animals.

- J. W. Trevan and A. M. P. Attwood are responsible for all experiments on 
diminished in size and the scab might take four to six days to form. The highest dilution per cent. at which slight necrosis occurs has been used to compare the various preparations studied and is denoted as the minimal necrosing concentration (M.N.C.).

Free acids.

M.N C. Diluent:

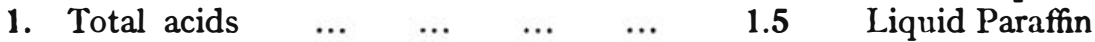

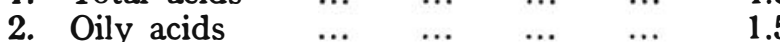

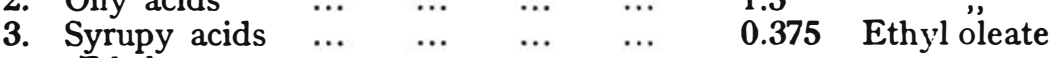

Ethyl esters.

4. Of total acids, distilled $185-215 \mathrm{deg}$./

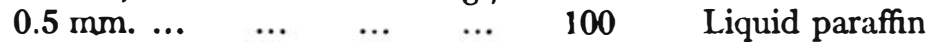

5. Of "Crystalline acids":-

(a) Dist. at 198-215 deg./14 m.m. 75

(b) Dist. at 345-355 deg. $/ 760 \mathrm{~mm} . \quad 75$

(c) 5 b steamed $\quad \ldots \quad \ldots \quad \ldots \quad 75$

(d) $5 \mathrm{~b}$ iodised $\quad \ldots \quad$ negative at 100

(e) $5 \mathrm{a}$ after exposure to air $\quad \ldots \quad 3$

6. Of oily acids, distilled $175-215 \mathrm{deg}$./
$0.5 \mathrm{~mm}$.
negative at 100

7. Of keto-acids, distilled $215-230 \mathrm{deg}$./

\section{$0.5 \mathrm{~mm} . . . \quad \ldots \quad \ldots . \quad \ldots$}

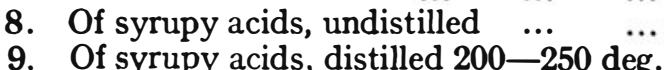

19 Ethyl oleate

38 Liquid paraffin
$0.5 \mathrm{~mm}$

10. Of tarry acids, undistilled

Sodium salts.
11. Of total acids

10

$\begin{array}{llll}\cdots & \cdots & \cdots & \ldots\end{array}$

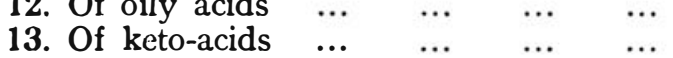

14. Of syrupy acids $\quad \ldots . \quad \ldots . \quad \ldots$.

15. Of tarry acids ...

...

$\ldots$

...

6.25 Ethyl oleate

2.25 Water

2.25

2.25

1.5

1.5

The crystalline acids, keto-acids and tarry acids were too insoluble in the free state for injection.

It is clear from these results that the crystalline acids and the oily acid are bland products when administered as esters. In comparison with the syrupy acids the oily acid is relatively inert as an irritant, even in the free state. Distillation of the ethyl esters of the crystalline acids at atmospheric pressure instead of at $14 \mathrm{~mm}$. does not increase their irritant quality, while the latter can still be reduced materially by iodisation. It should be noted, however, that iodised esters of the crystalline acids are less stable than iodised esters of the total acids. The ethyl esters of the keto-acids are clearly less bland than those of the crystalline and oily acids, but in the form of the sodium salts they are not more irritant than the sodium salts of these fractions, although the difference between any of the soaps is comparatively small. The "syrupy acids," their ethyl 
esters, cause a degree of irritation intermediate between that caused by the oily acids and the tarry acids, of which the syrupy acids mainly consist; this irritation is increased when the esters are distilled, and the tarry constituent thereby partly decomposed. The esters of the tarry acids and the exposed ethyl esters are far more irritant than any of the other products.

The practical outcome of these results may be stated as follows:-Stocks of chaulmoogra and hydnocarpus preparations should be kept in a cool, dark place in full bottles. Under these conditions they are quite stable. As it is not practicable constantly to transfer a stock actually in use to smaller bottles, the quantity issued from stock for use in a leper institution should not exceed, say, one month's supply.

REFERENCES.

(1) Henry, Sharp and Brown, Biochem. Jour., 19 (1925), 518.

(2) Muir.- "Leprosy : Diagnosis, Treatment and Prevention." 5th edition, p. 26.

(3) Perkins.-Philippine Jour. Sci., 21 (1922), 9.

(4) Jackson.-Lep. Rev., 3 (1932), 67.

(5) Andre.-Compt. rend., 181 (1925), 1089.

(6) Da Silva.-Rev. Brasileira Med. Pharm., 2 (1926), 627.

(7) Rothe and Surerus.-Rev. Soc. Bras. Chem., 2 (1931), 358.

(8) Dean and Wrenshall.-Jour. American Chem. Soc., 42 (1920), 2626.

(9) Hashimoto.-Jour. American Chem. Soc., 47 (1925), 2526. 